Copyright (C) 2018 by Academic Publishing House Researcher

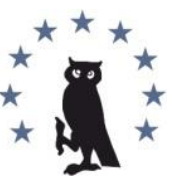

Published in the Russian Federation

European Researcher. Series A

Has been issued since 2010.

ISSN 2219-8229

E-ISSN 2224-0136

2018, 9(2): 171-175

DOI: 10.13187/er.2018.2.171

www.erjournal.ru

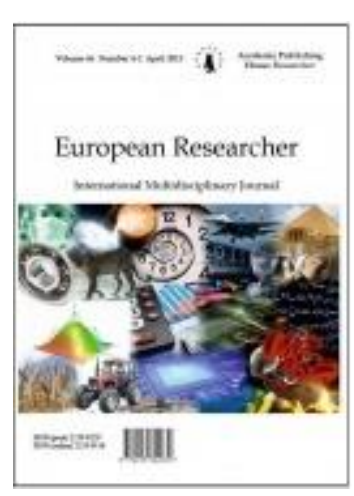

\title{
Variety of Proverbs in Literary Texts
}

Dilfuza S. Turdalieva ${ }^{a}$,

${ }^{a}$ Kokand State Pedagogical Institute, Fergana, Uzbekistan

\begin{abstract}
Proverbs are used in the oral speech in the form of variation. Variation of proverbs is connected with its ethnic and pragmatic peculiarity. Durability of proverbs is specific. Proverbs are stable as internally as externally. From this point of view they differ from expressions which have only internal durability. The usage of different proverbs in the oral speech depends on the speaker's and listener's condition, oral conditions and environment, text's peculiarity. This demands more understanding when we connect proverbs with their ethnic peculiarities

Proverbs can be divided into oral, methodological, ethnic and historic types. The scientific studying of proverbs has a great importance for academic and lexicographic appliance.

Keywords: generalizing, peculiarity, existence, phenomena, variation, stylistic variation, ethnic variation, historic variation, pragmatic variation, synonymy, difference, similarity, durability, change, phraseological accord, internal accord, external accord.

\section{Introduction}

Development of the oral speech's strategy of learners depends on the level of awareness of lexical ability. Thus, oral speech is connected with the linguistic basis, which is its foundation stone, i.e. its lexicographic basis.

Lexicographic sources give information about not only types of proverbs, but the place, method, time, ethnic environment of proverbs usage. As we see there is a problem of paremiologic variations for the lexicography as well as for their formation. First of all the difference between variation and synonymy of proverbs plays a great role. Variation and synonymy are not allowed totally not only in proverbs but in all linguistic accord.

The level of division of generalizing or variation and detachment. The word variant is formed from the word variation(Latin Variation - changing) means types of the certain unity having quantitative modifying difference.

Variation - a general term applied in different spheres. For example, in music, when not all elements, but some of the same topic are shown in a changed form (rhythm, tempo, melody, etc.) This constitutes musical variation. Thus, in musical variation some sides of the phenomena are shown saving their essence.

In music modification of variation can be different:

- Changing, which has relation with the essence.

- Changing, which doesn't have relation with the essence.
\end{abstract}

\footnotetext{
${ }^{*}$ Corresponding author

E-mail addresses: elnora85@mail.ru (D.S. Turdalieva)
} 


\section{Methodology of research}

The process of scientific researchers are passed to the general methods of researches, the methods of logical and systematic analysis, to make questionnaire, grouping, comparing are used. These methods helped to make conclusion in all stages of scientific researches.

\section{Literary analysis on the theme}

In changing, which doesn't have relation with the essence, the topic doesn't change. In changing, which has relation with the essence, a new topic is formed and the work becomes autonomous. In this case it's necessary to mention historic variation, which appeared as a result of variation, but from the point of view of the work's autonomy. In music of Europe till the XIX century variations of G. Persell, G. Gendel, I. Bach, V. Mozart, L. Beethoven works were created, which were created by the method of romanticism on the basis of variation (R. Shuman, P.Chaykovskiy, etc.) (Uzbekistan national encyclopedia, 1996: 389).

In the scientific researches in Uzbek linguistics the language of literary texts and variation of proverbs are enough researched. Variations of literary speech are appeared basically in the poetry. The individual method of each author is different and has individually norm and this norm plays important role. Famous Uzbek linguistic B. Umurqulov has researched the literary texts, and he has noticed the role of variation of proverbs in the system-structural aspect. He has used works of G. Gulomov, E. Vokhidov, A. Oripov and other authors.

Variation statistics, which is the branch of the mathematical statics, studies appearance of general features in the elements of statistical collection. Statistical collection includes many objects which are similar by the definite feature or the general phenomena. These general phenomena independently reflect the essence of the collection at some level. This reflection is measured by the qualitative and quantitative parameters. Statistics of variations on the basis of changing events of different individuals is peculiar to all biological objects in the homogeneous essence is widely studied in biology, genetics and agricultural selection. In this case the transformation of the quantitative into qualitative changings is explored in the appearance of the quality of homogeneous definite individuals on the basis of dialectical regularity.

In the case of the event appearance in homogenous changing on the definite individuals, two things attract special attention:

- The level of changing

- The cause of changing

The level of changing can be quantitative or qualitative. If changing is quantitative, it's necessary to mention the variation of the individual, if changing is qualitative, the appearance of a new individual can be concluded. Quantitative changings are done in every individual. But the quantitative changings are done rarely.

\section{Analysis and results}

Modification difference may be qualitative and quantitative. For instance, let's look at the difference between definitions of polysemantic lexeme. Quality (size) of united semes among separate semes can be fewer or more in comparison with the quantity of other semes. Let's study the verbs to extend, to spread: "to spread something (a rolled carpet)", "to spread a creased thing" (to spread a creased paper). The difference between the two words is the first case means rolled, in the second case means creased. In two cases we mean to spread and to smooth something. As we see actions are similar, but directed to the condition which should be corrected. In other words, general features are peculiar to the type of the action, but the differences to the state features, to which the action is directed. Here we can see the difference of generalization with the basis not belonging to the essence, when the essence is united on the basis of similarity determining the essence. We can conclude that the level of the difference in modification of the given meanings appears in the quantitative form, but doesn't reach the qualitative changing. Thus the level of the difference is lower than the level of similarity. From this point of view we can conclude that in variation we should pay attention to the following things:

- Generalizing under one accordance;

- Covering the accord of the form and the content;

- Absolute saving of the form's accord in the private meanings;

- The difference in the private meanings; 
- Less number of difference of meanings in comparison with its similarity;

- Differences which are not related with the essence;

- Similarities which are not the natural phenomena

Let's examine the second verb to spread, stretch which is homonym of the word to stretch time . In this case we can see the stem difference and the action. Actually all three actions have the meaning to spread, stretch something. But in the third case "to stretch" has the same meaning as in two previous action, but not to spread in its full meaning. The relation of the third action to two previous actions is the following:

- The third verb is similar to the previous, but not its full meaning;

- The object with the action with this meaning differs from the previous ones;

- These differences are socialized.

In this case we come across not with the variation, but with the homonymy. It is obvious that in homonymy because of the difference in the meaning, similarity of the forms doesn't have the sense. Social meaning of the difference and social characteristic feature of their application are the reasons of homonymy appearance.

\section{Variation and homonymy}

When we differentiate variation from synonymy it's necessary to differentiate form and type. But in the Uzbek language dictionaries there is no difference between the words' form and type. For instance, in the definition of the word form we can find reference to the word type (Uzbekistan national encyclopedia, 1996: 108).

As it was mentioned before, synonymy in comparison with the variant defines events which are independent. If the basis of homonymy has the similar form and independent meaning, the form as well as its independence are peculiar features to synonymy. In variation the only feature is the accord of the form and the difference not in the independent meaning. In synonymy the main thing is denotative similarity.

Each synonym in comparison with variation has relative difference in the independent meaning. If we explore proverbs, we can definitely see similarity in the form in the synonymy accord, similarity in the meaning.

While comparing variation and synonymy in proverbs, besides meaning,

a great attention should be paid to the qualities of the form. Accord in the expression is divided into theme and predicate. In defining the theme and predicate we should look at the content.

1. Power in unity;

2. United power - power, not united power - nothing;

3. If we unite five fingers, we'll have a fist.

All these three proverbs (translated from Uzbek) are in the thematic group "friendly" and they express the general definition "who is friendly, that is strong". If the meaningful theme is "be strong", the meaningful predicate is "friendship". It's well known that one should be strong, there are many means to be strong. In proverbs we can find only one means: friendship. Thus this part is given in the form of "novelty". In variation proverbs the thematic part has the same form and content, the predicate part consists of different expressive means, which have the general meaning (unity, united). But in synonymy proverbs the general meaning is saved, expressive means (a theme and predicate) are totally different. If we unite all five fingers we'll have a fist.

Table 1. The examples of synonymy proverbs are as following

\begin{tabular}{|l|l|}
\hline Peaceful people have blossoming orchards. & If there is peace, the population will raise. \\
\hline Language - is a beauty of the mind. & Language is the measurement of mind. \\
\hline The state in the unity of opinions. & Power is in unity. \\
\hline An empty mill has a stronger noise. & Meaningless words don't feed you. \\
\hline
\end{tabular}


Table 2. The examples of variation proverbs

\begin{tabular}{|l|l|l|l|}
\hline 1 variant & 2 variant & $\begin{array}{l}\text { Element providing } \\
\text { accord }\end{array}$ & $\begin{array}{l}\text { Element } \\
\text { providing accord }\end{array}$ \\
\hline $\begin{array}{l}\text { United power can not } \\
\text { be destroyed }\end{array}$ & $\begin{array}{l}\text { United power wins, } \\
\text { not united loses. }\end{array}$ & United & Not win \\
\hline $\begin{array}{l}\text { If you have power you } \\
\text { will win one person, if } \\
\text { you have knowledge } \\
\text { you will win } \\
\text { thousands. }\end{array}$ & $\begin{array}{l}\text { If power doesn't } \\
\text { knowledge. }\end{array}$ & Knowledge is power. & Win, will do \\
\hline Patience - pure gold. & $\begin{array}{l}\text { Patience - yellow } \\
\text { gold. }\end{array}$ & Patience & Pure gold, yellow gold \\
\hline $\begin{array}{l}\text { Language - scales of } \\
\text { the mind }\end{array}$ & $\begin{array}{l}\text { Language } \\
\text { measurement of the } \\
\text { mind }\end{array}$ & $\begin{array}{l}\text { Language } \\
\text { meales of the mind, } \\
\text { mind }\end{array}$ \\
\hline
\end{tabular}

If we pay attention there are some elements which are not included into elements providing accord or variation, they are not reflected in this table to avoid tautology.

There are several factors which prevent differentiating variation and synonymy proverbs. In particular, diversity of proverbs is the object for studying different subjects such as linguistics, literature, ethics, ethnology, sociology. For example, in order to differentiate variation and synonymy in linguistic proverbs we should pay attention to the form and meaning, folklorists mix up variation and synonymy to form some ideas, but it cannot be criticized as each branch has its own criteria. In general, we should take into consideration the fact that variation and synonymy of proverbs are semantic, morphological, syntactic, methodological case (Meteva, 1991: 83).

There are situations when folklorists do not approve the cases when it is not correct to differentiate variation and synonymy in proverbs (Permyakov, 1998: 137). It is obvious that linguistics and folklore studies are at different level of the development, in particular similarity between structural folklore studies and structural linguistics is observed on the basis of research methods.

As proverbs are considered as stable expressions, their specificity is the integrity of their form and content, as well as constancy. That is why it's necessary to pay attention to constancy of proverbs in studying the structural specificity of variation and synonymy proverbs. In providing stability of the text of proverbs constancy of lexical units plays a great role. There are reasons and factors which provide this constancy. In their consequence we can identify the following things:

- Proverbs have social nature

- Traditional way of thinking

- Methodological feature of proverbs

- Relative high position of the influential power of proverbs

- Proverbs have euphemism features

Constancy of proverbs provides the integrity of proverbs with phraseological units. When we speak about stability of phraseological units we can speak about linguistics. But in this case stability of proverbs is different from the expressions. Phraseological expressions have the status of one word (lexeme), proverbs grammatically are formed and the speaker does not pay attention to their grammatical form. Any proverb has a present or future meaning and definite inclination, the form of the singular/plural third person, the form of confirmation/rejecting something and exists in the social consciousness. As phraseological expressions have the nature of lexemes, it is necessary to form grammatically in order to include them into the structure of the sentence. In this sense as A.V. Kunin mentioned "the stability of phraseological units is observed only in its ready state of expression" (Kunin 1970: 76) which can be used to the internal stability of phraseological expressions. It's obvious that we should speak about stability of stable expressions with the complex content, we should differentiate the internal and external stability as well.

As internal stability we mean the relation between elements which compose expressions. In general, words in the sentence, words and expressions in proverbs have mutual stable relation 
and this stability has social feature. The words in the stable expressions can not be replaced by synonyms and variants, these words and the sentences in proverbs which are grammatically formed and became stable expressions can be called internal stability. In comparison with proverbs, we can admit that phraseological unit has the similar form and content as a lexeme which is not grammatically formed and ready for the oral speech. For instance, in expressions whale of a mouth, to be disappointed, to sit in the puddle, lasso and etc. we can not see grammatical form. But some expressions are formed in the from of Subject + Verb and from the first sight it seems that the subject and the verb are ready for expressing the oral speech. But the variety of the mentioned above expressions shows the following: He was disappointed. I was surprised to see his disappointment. But in proverbs we can rarely see this case:

1. First think, then correct;

2. Hostility does not win justice wins;

3. Who conceals a mistake won't become rich;

4. Who goes far will be eaten by a bear. (translated from Uzbek).

Even when proverbs as ready syntactic structures play a role in the sentence structure of other sentences, their structure stays the same: Teachers said: "First think, then correct". We heard the proverb: "First think, then correct". Thus people created this proverb "First think, then correct", as other proverbs this proverb has pragmatic feature. If we pay attention, proverbs are not only independent sentences, but in transforming as a member of the sentence they save the form of the sentence. It shows that proverbs have internal and external stability, i.e. they are one level higher than expressions.

\section{Conclusion and recommendations}

Thus, when we speak about the stability of phraseological units, we should understand that constancy of lexical units, which is its structural part and grammatical connection became stable. In this sense a linguist S.N. Savitskaya mentions: "When we speak about the stability of phraseological units we understand constancy of their structure, which appears as a result of their frequent use" (Savitskaya, 1962: 39). She is totally right and shows her disagreement with A.V. Kunin about "ready expressions". Thus, constancy and derivative features are peculiar to the expressions and proverbs.

Proverbs regardless what meaning they express, pragmatic circumstances are not peculiar to them. Each separate circumstance has general content. Proverbs are considered to be a small genre, which serves as the basic sign providing the quality of their stability as shortening is not peculiar to fables. This characteristic feature makes proverbs and riddles different from larger folklore genres. This is especially can be based on the level of proverbs' stability in the simple sentence in comparison with the proverbs in the complex sentences. Many ethnic variants of proverbs certainly do not effect on the quality of the stability. Each ethnic variant is considered to be a stable phenomena for the ethnic thinking and speech. Literary variants serve as a factor of proverbs' stability. As there is a limit of saving stability in the general environment of one proverb other variants of proverbs appear to serve the stability.

\section{References}

Kunin, 1970 - Kunin A.V. (1970). English phraseology. M.

Mengliev, 2010 - Mengliev B. (2010). Language as a single unit, $\mathrm{T}$.

Mengliev et al., 2007 - Mengliev B., Khudoyberdieva O., Khudoyberdieva M. (2007).

Dictionary of phraseological units in Uzbek, $\mathrm{T}$.

Meteva, 1991 - Meteva E. (1991). Russian folklore. Sophiya.

Nematov, Bozorov, 1999 - Nematov H., Bozorov M. (1999). Language and speech, T.

Permyakov, 1998 - Permyakov G.L. (1998). Paremiology. M.

Rahmatullaev, $1970-$ Rahmatullaev Sh. Beauty of language, T.

Savitskaya, 1962 - Savitskaya S.N. (1962). On the stability of phraseological units. Questions of the English and Deutch languages theories. Kiev.

The dictionary, 1996 - The dictionary of the Uzbek language. $2^{\text {nd }}$ edition T, 1996.

Uzbekistan national encyclopedia - Uzbekistan national encyclopedia. 2 edition, T, 1996. 